\title{
Review of advanced catheter technologies in radiation oncology brachytherapy procedures
}

This article was published in the following Dove Press journal:

Cancer Management and Research

16 July 2015

Number of times this article has been viewed

\section{Jun Zhou',2 \\ Leonid Zamdborg' \\ Evelyn Sebastian'}

'Department of Radiation Oncology, Beaumont Health System, ${ }^{2}$ Oakland

University William Beaumont School of Medicine, Royal Oak, MI, USA
Correspondence: Jun Zhou Department of Radiation Oncology, Beaumont Health System, Oakland University William Beaumont School of Medicine, 360I West Thirteen Mile Road, Royal Oak, MI 48073, USA

Tel +l 24855 I 7078

$\mathrm{Fax}+|24855| 3784$

Email jun.zhou@beaumont.org
Abstract: The development of new catheter and applicator technologies in recent years has significantly improved treatment accuracy, efficiency, and outcomes in brachytherapy. In this paper, we review these advances, focusing on the performance of catheter imaging and reconstruction techniques in brachytherapy procedures using magnetic resonance images and electromagnetic tracking. The accuracy of catheter reconstruction, imaging artifacts, and other notable properties of plastic and titanium applicators in gynecologic treatments are reviewed. The accuracy, noise performance, and limitations of electromagnetic tracking for catheter reconstruction are discussed. Several newly developed applicators for accelerated partial breast irradiation and gynecologic treatments are also reviewed. New hypofractionated high dose rate treatment schemes in prostate cancer and accelerated partial breast irradiation are presented.

Keywords: catheter technologies, catheter reconstruction, electromagnetic tracking, hypofractionated high dose rate treatment, accelerated partial breast irradiation

\section{Introduction}

The field of radiation therapy has seen great progress in the past decade. While substantial advances have been made in external beam therapy, as a result of development of intensity modulated radiation therapy, ${ }^{1-3}$ volumetric modulated arc therapy, ${ }^{4}$ and other techniques, brachytherapy has also seen exciting improvements because of the development of new applicator and catheter technologies. For both types of treatment, advanced imaging guidance has given physicists and physicians the confidence to deliver hypofractionated treatments safely. As with innovations in multi-leaf collimators and accelerator design for external beam therapy, new catheter-related technologies, together with new sources and applicators, make advanced brachytherapy treatments possible.

Brachytherapy, ie, the delivery of radiotherapy from a source placed close to the target site, is one of the oldest forms of radiation therapy. In 1901, Pierre Curie loaned a quantity of radium to the famed dermatologist Henri-Alexandre Danlos for the purpose of treating cutaneous conditions. Over a century later, brachytherapy is one of the most important modalities for the treatment of malignancies. Brachytherapy has been involved in the treatment of nearly all sites in radiation therapy. There are two broad categories of brachytherapy, low dose rate (LDR) and high dose rate (HDR). Permanent or temporary LDR implants include those for the treatment of brain tumors, including metastases and glioblastoma multiforme, using a GliaSite (IsoRay Medical Inc., Richland, WA, USA) applicator filled with either ${ }^{125} \mathrm{I}$ or ${ }^{131} \mathrm{Cs},{ }^{5,6}$ ocular tumors using an eye plaque loaded with ${ }^{125} \mathrm{I},{ }^{103} \mathrm{Pd}$, or ${ }^{106} \mathrm{Ru}$ seeds, ${ }^{7-10}$ lung cancer using ${ }^{125} \mathrm{I}$ 
seeds in a Vicryl mesh, ${ }^{11}$ breast cancer using ${ }^{125} \mathrm{I}$ inserted into interstitial catheters, ${ }^{12}$ prostate cancer using ${ }^{125} \mathrm{I},{ }^{131} \mathrm{Cs}$, or ${ }^{108} \mathrm{Pd}$ seeds permanently implanted into the gland, ${ }^{13,14}$ and gynecologic cancers using ${ }^{137} \mathrm{Cs}$ tubes in a Fletcher-Suit or Henschke applicator. ${ }^{15,16}$ HDR brachytherapy, on the other hand, with a more flexible dose distribution, no radiation exposure to health care personnel, and lower patient cost, has drawn much more attention in the field of radiation oncology recently. In an HDR treatment, an ${ }^{192}$ Ir source is transported through multiple catheters or multiple channels in an applicator to the center of or in proximity to the target, and delivers the planned dose by keeping the source staying at designated dwell positions for varying amounts of time. Any tumor that can be accessed with catheters or an applicator can be treated with HDR. With the development of new applicator and catheter technologies, as well as image guidance, HDR procedures are replacing LDR procedures in most clinical situations involving brachytherapy.

LDR permanent seed implants have been used extensively since the 1980 s for prostate cancer, and have been recommended for the treatment of organ-confined low-risk and some intermediate-risk patients. ${ }^{14,17,18}$ Long-term outcomes showed that the prostate-specific antigen relapse-free survival at 8 years was $93 \%$ for patients treated with ${ }^{125} \mathrm{I}$ implants where the dose to $90 \%$ of the prostate was $>130$ Gy. ${ }^{19}$ Recently, thinner 20-gauge seed implant needles have been applied clinically for the purpose of reducing traumaassociated edema. The initial report demonstrated improved dosimetry due to reduced trauma and less perineal pain. ${ }^{20}$ HDR prostate brachytherapy, originally used as a boost together with external beam treatment, has been receiving more attention as monotherapy for suitable patients, due to its better-controlled dosimetry, no residual radioactivity, higher dose rate, and better suitability for low $\alpha / \beta$ ratio prostate cancer. The results of clinical trials show that it has outcomes similar to those of LDR brachytherapy, ${ }^{21}$ while reducing most toxicities. ${ }^{22}$ Typically, in a template-guided prostate HDR implant, 15-18 catheters are inserted through the perineum into the prostate, under the guidance of transrectal ultrasound (TRUS). The treatment plan can be based either on the TRUS images or on a computed tomography (CT) scan of the patient with all the catheters in place.

Accelerated partial breast irradiation (APBI) has been used extensively for the treatment of breast cancer, as it has been noted that recurrences following whole breast radiotherapy are mostly at the tumor bed. ${ }^{23,24}$ The first brachytherapy technique for delivering APBI, interstitial breast brachytherapy, is not common in the USA due to high operator training requirements.
More recently, single-entry balloon applicators, such as the single-lumen and multi-lumen MammoSite (Hologic, Bedford, MA, USA) and Contura (SenoRx Inc., Irvine, CA, USA) applicators, have been extensively used in partial breast treatment. The outcomes, side effects, and cosmetic results have been studied in many national and institutional trials. ${ }^{25,26}$ Recently, Cuttino et al reported the outcome of a Phase IV multi-institutional trial using the Contura device. The local recurrence rate was $2.8 \%$, and $88 \%$ of patients had good to excellent cosmesis at a median follow-up duration of 3 years. ${ }^{27}$ We have reported the 5-year outcomes and cosmetic results for the randomized National Surgical Adjuvant Breast Project B-39 trial of whole breast irradiation versus partial breast irradiation, ${ }^{28-30}$ and found that the 5-year actuarial ipsilateral breast recurrence rate was $3.8 \%$, and $90.4 \%$ of the patients had excellent/good cosmetic results at 72 months post-treatment. Factors predicting recurrence were negative estrogen receptor status $(P=0.0011)$ for invasive breast cancer, while age $<50$ years $(P=0.0096)$ and positive margin status $(P=0.0126)$ were associated with recurrence in patients with ductal carcinoma in situ. Predictors associated with worse cosmetic outcome were skin spacing and tumor size. In addition to these findings, patients with skin spacing $<5 \mathrm{~mm}$ ( $<7 \mathrm{~mm}$ at some institutions) were not eligible for treatment with these balloon applicators. To overcome this skin distance limitation, a new applicator, the strut-adjusted volume implant (SAVI; Cianna Medical, Aliso Viejo, CA, USA), has been recently developed. It has better skin-sparing capability, and thus allows an increase in eligibility for APBI. Although it does have a high V200 volume (as the irradiated tissue is much closer to the source dwell positions), initial studies have shown that it can provide better dosimetry to the target while minimizing the dose to the skin and ribs, with a low incidence of side effects. ${ }^{31}$ However, long-term toxicity and cosmetic studies are not yet available.

Brachytherapy also plays a key role in treating patients with uterine and cervical cancer. The Manchester system, which is the most commonly used dosimetric system, dates back to $1938 .{ }^{32}$ It was later updated to the revised Manchester system, ${ }^{33}$ in which the prescription has been traditionally tied to Point A, which is based on applicator geometry rather than target and patient anatomy, and represents the tolerance dose of a critical structure (uterine vessels), rather than the tumoricidal dose to a target structure. In a 2007 survey, 60\% of institutions still used this method. ${ }^{34}$ Although simple and effective, this method has been shown to frequently underdose the target and overdose the critical structures, due to variations in human anatomy. International Commission on 
Radiation Units and Measurements Report 38 was intended to standardize treatment planning and reference volumes, but was not well accepted in the clinic. ${ }^{35}$ To increase the therapeutic ratio and take advantage of image guidance, both the European Society for Radiotherapy and Oncology (ESTRO) $)^{36,37}$ and the American Society for Therapeutic Radiology and Oncology ${ }^{38}$ have published guidelines for using volumetric imaging, especially magnetic resonance (MR) imaging, for target delineation, and for using dose-volume histogram parameters for target coverage, hotspot identification, and organ at risk dose reporting. Recently, the American Brachytherapy Society published consensus guidelines for gynecologic procedures. ${ }^{39-41}$ The trend in gynecologic brachytherapy is to use HDR rather than LDR, with volumetric image-based planning, especially MR imaging. ${ }^{42-44}$ Recent studies demonstrated improved dosimetry with three-dimensional image guidance and use of ESTRO guidelines. ${ }^{45,46}$ Recently developed and updated applicators and catheter techniques for gynecologic brachytherapy are aimed to make applicators CT/MR-compatible, MR-visible, cause fewer artifacts in MR images, ${ }^{47-51}$ and extend coverage area and flexibility by modifying traditional applicators. ${ }^{52-54}$ For example, the new CT/MR Fletcher applicator with moveable shielding incorporated in the ovoids can reduce the dose by up to $50 \%$ in the anterior-posterior direction. ${ }^{55-57}$

Beyond prostate, breast, and gynecologic applications, HDR brachytherapy has been used for treatments of the pituitary, ${ }^{58}$ external auditory canal, ${ }^{59}$ upper gum,,${ }^{60}$ tongue, ${ }^{61,62}$ ethmoid sinus sarcoma, ${ }^{63}$ stomal recurrences of laryngeal tumors, ${ }^{64}$ other sites of the head and neck, ${ }^{65-68}$ spine, ${ }^{69}$ liver, ${ }^{70}$ colorectal endoscopic brachytherapy, ${ }^{71,72}$ and extremity sarcomas.

New catheter technologies have been applied to every aspect in brachytherapy. Below, we will focus on their applications in image guidance, catheter reconstruction, and extended coverage via newly developed applicators.

\section{New catheter technologies in brachytherapy}

After identifying the target, the key factors in a brachytherapy procedure are choosing appropriate sources and applicators, accurately placing them at the tumor or treatment location, identifying the sources or reconstructing the catheter track correctly, planning the treatment accordingly, and keeping the catheters in the same position during all subsequent fractions, so as to precisely deliver the planned dose. Most of the radioactive seeds and sources are delivered to the treatment region via a catheter and applicators. Except for interstitial brachytherapy treatments, the catheters are always in the form of a specialized applicator. Applicators are usually easier to place, reconstruct, and plan with, and result in more predictable dosimetry. Numerous new applicators have been developed recently to address different clinical aspects of various body sites, provide better visualization in various imaging modalities, provide better handling and implanting, or allow better dosimetry at the target.

\section{Multi-modality image guidance of catheter/applicator insertion, reconstruction, and verification}

Image guidance plays a key role in modern brachytherapy procedures, especially in the GEC-ESTRO guidelines for gynecologic brachytherapy. ${ }^{36,37,73}$ Tanderup et al recently reviewed the application of MR imaging and its advantages/ limitations in brachytherapy. ${ }^{74}$ With the increasing prevalence of MR imaging in brachytherapy, many classical applicators have been modified to be not only CT-compatible, but also MR-compatible. Nucletron (now Elekta AB, Stockholm, Sweden) has Fletcher, ring, and tandem applicators available in a plastic material for CT/MR compatibility. Varian Medical Systems Inc. (Palo Alto, CA, USA) provides titanium gynecologic applicators for the same purpose. Although mechanically stronger and more compact than their plastic counterparts, titanium applicators show strong susceptibility to distortion and artifacts in MR imaging. These artifacts appear as signal hypointensity around the applicators. The extension and location of the artifacts depend on many factors. Lewin et al investigated the impact of these factors on needle localization in MR-guided biopsy in $1996 .{ }^{75}$ Although applicators in brachytherapy are much larger than biopsy needles, most of their findings still apply: higher MR main magnet $\mathrm{B}_{0}$ strength is associated with greater artifact; a smaller angle between the needle and $\mathrm{B}_{0}$ results in less artifact; and the MR scanning sequence plays a key role in determining the extent and amplitude of artifacts.

Haack et $\mathrm{a}^{47}$ and Petit et $\mathrm{al}{ }^{50}$ studied titanium applicator reconstruction in phantoms and patients using 1.5 T MR images. Although the artifact width for titanium tandems varied with the relative angle between the tandem and $\mathrm{B}_{0}$, both reported reaching submillimeter accuracy in localizing the center of the tandem in phantom studies, due to the symmetric round shape of the tandem. However, the tip of the tandem was much harder to localize, as a result of not only uncertainty in artifact extension, but also in data sampling from the relatively large slice thickness of MR imaging. In patient studies, both groups reported interobserver accuracy 
results, as CT images were not used as a "gold-standard" reference for clinical patients. As both studies used different MR scan protocols and applicators, both reported different reconstruction accuracies. Haack et al used a T1-weighted turbo spin-echo sequence with $0.8 \times 0.8 \mathrm{~mm}$ in-plane resolution and $3 \mathrm{~mm}$ slice thickness, and reported an interobserver accuracy of $-0.9 \pm 2.3 \mathrm{~mm}$ for tandem tip localization. Although Lewin et al mentioned that artifact was more pronounced with gradient-echo sequences than with turbo spin-echo sequences, higher artifact is not necessarily associated with lower reconstruction accuracy. By increasing the contrast between soft tissue and the applicator using a spoiled gradient-echo sequence with $1.6 \times 1.6 \mathrm{~mm}$ in-plane resolution and $1.6 \mathrm{~mm}$ slice spacing, Petit et al were able to reach a mean interobserver accuracy of $0.7 \mathrm{~mm}$ and a maximum deviation $<1.7 \mathrm{~mm}$. They accomplished this by using an applicator model, which used the outline of the ovoid and the direction of the tandem as a reference, because of their fixed geometry. Recently, Schindel et al have proposed use of a marker flange on titanium tandems, and reported an accuracy of $0.42 \pm 0.14 \mathrm{~mm}$ for localization of the marker flange when using $\mathrm{CuSO}_{4}$ as the marker filling material in a 3 T T1-weighted MR scan with a three-dimensional voxel size of $1.2 \times 0.9 \times 1.0 \mathrm{~mm} .{ }^{49}$ The same group also investigated the artifact and distortion of titanium tandem and ovoid and tandem and ring applicators in 3T MR scans. ${ }^{48}$ Instead of determining the accuracy of reconstruction, they tried to quantify the actual artifact width. In a phantom study, they found that the artifact's width at the tandem tip for both tandem and ovoid and tandem and ring was $1.5 \pm 0.5 \mathrm{~mm}$ in the superior direction. Similar results were found for the ovoids. In a patient study, the width of the artifact for the tandem was $<2.6 \pm 1.3 \mathrm{~mm}$. The distortion was $<1.2 \pm 0.6 \mathrm{~mm}$.

Both Haack et al and Schindel et al studied plastic catheter reconstruction with $\mathrm{MR}$ imaging. Haack et al reported a $1.1 \mathrm{~mm}$ and $0.6 \mathrm{~mm}$ deviation from CT reconstruction for the tip of the tandem and the center of the ring source channel, respectively, in a phantom study using a custom-made $\mathrm{CuSO}_{4}$ filled dummy plastic catheter in a $1.5 \mathrm{~T}$ MR scan. Schindel et al investigated signal intensities for different marker agents in a $3 \mathrm{~T}$ MR scan. ${ }^{49}$ They found that $\mathrm{CuSO}_{4}$ generated the best hypersignals in T1-weighted MR sequences, and saline is the best agent for T2-weighted MR sequences.

\section{Electromagnetic tracking}

In brachytherapy, catheter reconstruction is one of the most important procedures in treatment planning, and relates the source tracks and dwell positions to the patient's anatomy (eg, targets and organs at risk). As discussed previously, investigators have tried to improve the fidelity of detectability and visualization of catheters and applicators on imaging. However, due to the intrinsic limitations of some imaging modalities, it is difficult to accurately reconstruct catheters. For example, in a TRUS-based real time prostate HDR implant procedure, a treatment plan is generated in real time and the treatment is delivered while the patient is still in the same position. As the dosimetry of a treatment plan is directly related to needle positions, accurate catheter reconstruction is critical for accurate dosimetry. However, as shown in Figure 1, this is highly challenging, due to degraded ultrasound images from tissue speckles, calcifications, and in some cases, radiopaque markers. In addition, interference between catheters, due to signal reflection and interchannel crosstalk, further deteriorates catheter identification and thus reconstruction. As image resolution decreases with increasing distance from the probe, the catheter localization accuracy in the anterior part of the image is further decreased. Studies have shown that ultrasound beam width artifacts, an obscured needle tip, and a slightly bent ultrasound probe can result in greater than $5 \mathrm{~mm}$ errors in catheter tip localization. ${ }^{76-78}$ When a catheter is shadowed by another catheter posteriorly, or is close to strongly reflecting objects, its reconstruction can be very unreliable. Wilkinson and Kolar recently investigated medical event reports on the Nuclear Regulatory Commission website for HDR-related events for the years 1999-2012. ${ }^{79}$ Of all 44 events reported, 29 were related to catheter reconstruction, including wrong index length, wrong catheter track identification, and misidentification of first dwell position.

To address these challenges in catheter reconstruction and thus improve dosimetric accuracy, we first introduced and implemented an electromagnetic tracking (EMT) system to automatically track catheter positions, increasing the accuracy and speed of the catheter reconstruction process. ${ }^{80}$ EMT has been used for interventional radiology, ${ }^{81}$ guidance of intraoperative surgical procedures, ${ }^{82-84}$ and radiation therapy. ${ }^{85}$ EMT uses a three-pole transmitter to generate an electromagnetic field. One or more sensors located in the electromagnetic field generate voltages proportional to their distance from the transmitter, which are then used to calculate positional and angular information. Two EMT techniques exist, ie, alternating current (AC) tracking and direct current (DC) tracking. In AC tracking, because the rapidly varying electromagnetic field continuously induces eddy currents in nearby metals, the field may be distorted, causing error and noise. With DC tracking, however, pulsed DC fields quickly reach a steady magnetic state soon after 
transmission. By adjusting sampling rates to times when eddy currents are decaying or have died out, DC trackers can theoretically operate with minimal or no distortion. However, in practice, EMT still suffers substantial interference if not configured carefully and correctly. The performance of EMT in HDR catheter reconstruction depends on the accuracy of the EMT system itself, as well as its ability to resist noise and interference from the surrounding environment, the accuracy of the registration between the EMT results and the ultrasound/CT image data set, and the calibration scheme used to correct for nonuniform distortions resulting from metal interference.

\section{EMT system accuracy}

The factors that affect EMT system accuracy include: the inverse relationship of accuracy versus the distance between the field generator (FG) and the electromagnetic sensor; the electromagnetic noise from the outside environment and the electronic noise from within the acquisition circuit; and distortion of the magnetic field by ferromagnetic or other metallic materials. The variations of the magnetic field generated by an FG in an AC or quasi-DC system induce eddy currents in metals, causing distortions in the electromagnetic field. Ferromagnetic materials themselves add additional distortion, as they have an inherent magnetic field. The positioning error of a sensor, $\Delta r$, introduced by these types of interference, has the following relationship with distance: ${ }^{86}$

$$
\Delta r \propto \frac{d_{t r}^{4}}{d_{t m}^{3} \cdot d_{m r}^{3}}
$$

where $d_{t r}, d_{t m}$, and $d_{m r}$ are the distances from the FG to the sensor, the FG to a metal object, and the metal object to the sensor, respectively. Positioning error thus decreases with a decreased sensor to FG distance, an increased metal object to FG distance, and an increased metal object to sensor distance. The electronic noise is mostly Gaussian-distributed, and can be reduced by averaging more sampling points, at the expense of lower tracking speed. Reducing sampling frequency in a quasi-DC system can alleviate the eddy current effect, but cannot correct for the intrinsic interference of ferromagnetic materials. ${ }^{86}$ In addition, the signal to noise ratio of an EMT system can be improved by increasing the strength of the FG and increasing the size of the electromagnetic sensors.

In our study, a DC electromagnetic FG (mid-range model) and a 6 degree-of-freedom sensor with a diameter of $1.3 \mathrm{~mm}$ (Model 130) were used in a trakSTAR system (Ascension Technology Corporation, Shelburne, VT, USA, as shown in Figure 2) for tracking catheter positions during prostate HDR brachytherapy. According to the manufacturer, this FG and sensor combination can provide a $46 \mathrm{~cm}$ working range from

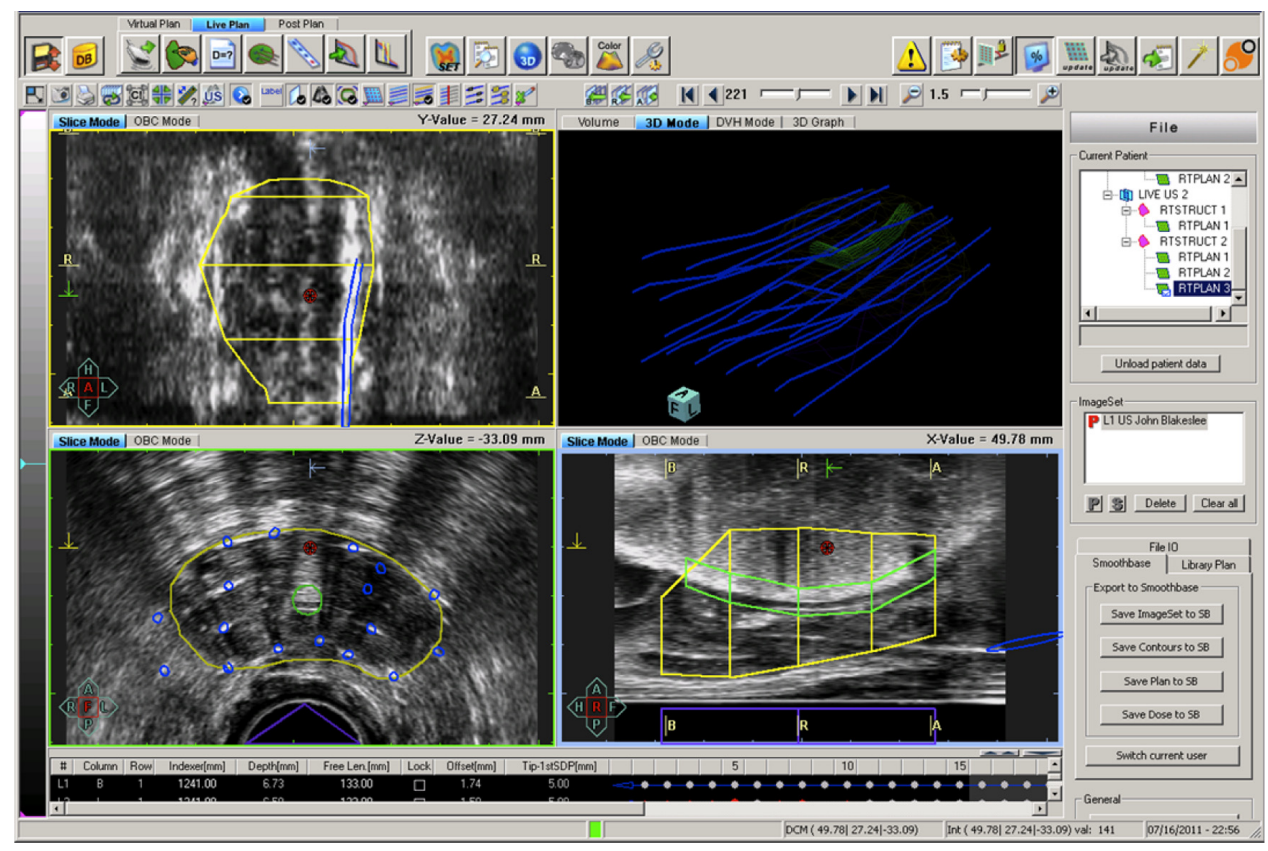

Figure I Prostate (yellow contour), uretheral (green contour), catheters (white dots in the axial image), and their reconstructions (blue circles and catheters) shown in a TRUS image-based prostate high dose rate planning system. The coronal, axial, and sagittal views of the TRUS image are shown in the left upper, left lower, and right lower panes, respectively.

Abbreviation: TRUS, transrectal ultrasound. 


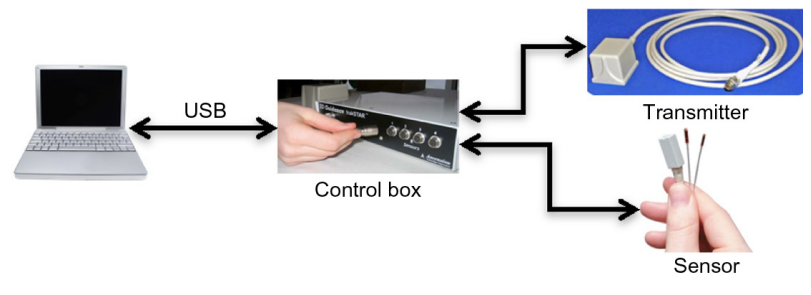

Figure 2 Electromagnetic tracking system components. A computer communicates with the control box through a USB interface. Both transmitter and sensor are connected to the control box.

Abbreviation: USB, universal serial bus.

the center of the FG. Localization accuracy was assessed using a calibration phantom with known catheter positions, as shown in Figure 3. The effects of the relative positions between the electromagnetic sensor and FG, the surrounding environment, and sampling frequencies were investigated. Our initial results showed that the performance of an EMT system can be improved by reducing the interference from surrounding equipment, decreasing the distance from the FG to the tracking area, and choosing an appropriate sampling frequency. An accuracy of $0.9 \pm 0.2 \mathrm{~mm}$ was obtained for dynamic tracking when using the optimum configuration.

Recently, Bharat et al reported a similar study that used EMT for catheter reconstruction in prostate HDR brachytherapy. ${ }^{87}$ An AC EMT system was used for this study. By attaching electromagnetic sensors to a robotic arm, the static localization accuracy of the electromagnetic system was evaluated both in an ideal environment and with distorting equipment present. An accuracy of $0.26 \pm 0.16 \mathrm{~mm}$ was achieved in the ideal environment. The error increased to $>2 \mathrm{~mm}$ when distorting equipment (a 20 inch LCD monitor) was approaching $30 \mathrm{~cm}$ of the center of the FG.

Poulin et al reported their results using EMT for catheter reconstruction in HDR brachytherapy. ${ }^{88}$ A second-generation Aurora planar FG (Northern Digital Inc., Waterloo, Canada)

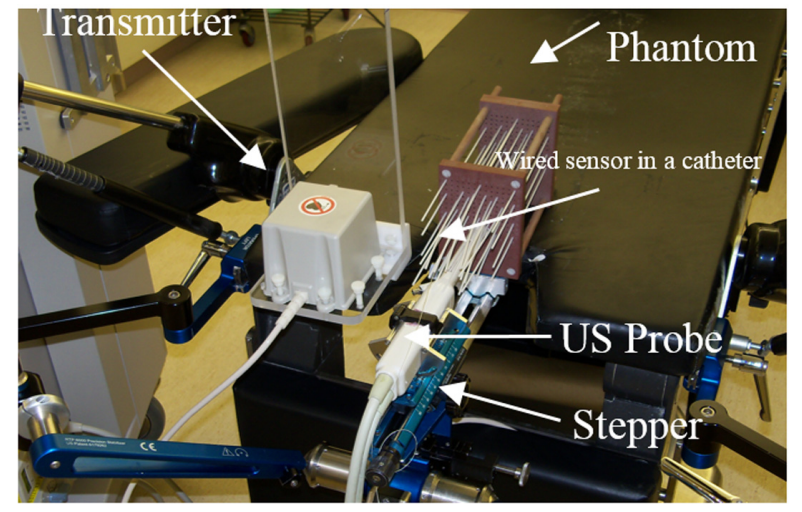

Figure 3 Electromagnetic tracking system setup and performance investigated using a calibration phantom. with a stated accuracy of $0.7 \mathrm{~mm}$ in positioning and $0.2^{\circ}$ in orientation was used. A Philips Percunav ${ }^{\mathrm{TM}} 18 \mathrm{G} \times 15$ $\mathrm{cm}$ biopsy needle (Philips Electronics NV, Eindhoven, the Netherlands) was used in this study. 6-French catheters were inserted into a gelatin phantom, which was then scanned with a micro-CT (GE Healthcare, Fairfield, CT, USA). Reconstruction was performed with an isotropic resolution of $89 \mu \mathrm{m}$ in three dimensions, and the identified catheter tracks were used as the reference. The phantom was then scanned with a conventional CT (Philips Big Bore, Philips Medical, Amsterdam, the Netherlands) as well, using a $2 \mathrm{~mm}$ slice thickness and $0.375 \mathrm{~mm}$ resolution in axial images. Catheters were tracked with EMT in an ideal environment. Reconstruction results from both conventional CT and EMT were registered to the reference using an iterative closest point algorithm employing a finite difference method. ${ }^{88} \mathrm{An}$ accuracy of $1.08 \pm 0.72 \mathrm{~mm}$ and $0.66 \pm 0.33 \mathrm{~mm}$ was achieved with $\mathrm{CT}$ reconstruction and EMT reconstruction, respectively. The inferior accuracy from CT-based reconstruction was attributed to the $2.0 \mathrm{~mm}$ slice thickness of the CT images. Table 1 lists all reports that mentioned using EMT for catheter tracking.

\section{Registration between different coordinate systems}

As data from an EMT system is based on the coordinates of the FG, it has to be transformed to the treatment planning coordinate system $\mathrm{C}_{\mathrm{RTplan}}$ (in a typical prostate HDR planning system, this is usually based on the position of the implant template grid). A rigid registration is usually conducted based on three or more points, the positions of which are known in both coordinate systems. The registration points used are the catheter tip positions from the most posterior catheters, the tip positions of which can be clearly identified in TRUS images. Several other registration points can be chosen at free holes (holes without needles) on the template. The system yields two data sets; the first consists of the coordinates of selected registration points exported from the treatment planning system, while the second consists of the positions of the same registration points in electromagnetic FG coordinates. An algorithm is then used to find the best transformation between the two coordinate systems using these two data sets. As the location errors from the EMT system are anisotropic (depending on the sensors' distances to the electromagnetic FG, noise, and interference), an iterative optimization approach with anisotropic weighting is used. ${ }^{89}$ In addition to the errors resulting from EMT, there are likewise uncertainties in identifying catheter tip positions in TRUS images, due 
Table I Accuracy of electromagnetic tracking from recent reports

\begin{tabular}{|c|c|c|c|c|c|}
\hline Reference & Year & $\begin{array}{l}\text { EMT field generator } \\
\text { and type }\end{array}$ & $\begin{array}{l}\text { EMT sensor and } \\
\text { diameter }\end{array}$ & $\begin{array}{l}\text { Test condition and } \\
\text { environment }\end{array}$ & Accuracy $(\mathrm{mm})$ \\
\hline \multirow[t]{2}{*}{ Zhou et al ${ }^{80}$} & 2013 & $\begin{array}{l}\text { Ascension trakSTAR, } \\
\text { DC }\end{array}$ & Model I $30,1.3 \mathrm{~mm}$ & $\begin{array}{l}\text { Absolute, in OR without } \\
\text { interfering equipment nearby }\end{array}$ & $0.5 \pm 0.2$ \\
\hline & & & & $\begin{array}{l}\text { Absolute, in OR with interfering } \\
\text { equipment nearby }\end{array}$ & $0.9 \pm 0.2$ \\
\hline \multirow[t]{6}{*}{ Bharat et $\mathrm{a}^{87}$} & 2014 & Aurora EMT system, DC & $1.2 \mathrm{~mm}$ & Absolute, in an ideal environment & $0.26 \pm 0.16$ \\
\hline & & & & $\begin{array}{l}\text { Absolute, in an ideal environment } \\
\text { with distorting equipment at } 30 \mathrm{~cm}\end{array}$ & $>2$ \\
\hline & & & & Post registration, EMT versus & IP: $0.7 \pm 0.3$ (maximum I.7) \\
\hline & & & & TRUS in ideal environment & OP: $0.1 \pm 0.1$ (maximum 0.2 ) \\
\hline & & & & Post registration, EMT versus & IP: $0.6 \pm 0.3$ (maximum I.5) \\
\hline & & & & TRUS in OR & OP: $0.4 \pm 0.2$ (maximum 0.6 ) \\
\hline \multirow[t]{2}{*}{ Poulin et a $\left.\right|^{88}$} & 2015 & Aurora planar FG, AC & Philips Percunav ${ }^{\mathrm{TM}}$ I8G & Post registration, EMT versus & IP: $0.66 \pm 0.33$ \\
\hline & & & $\times 15 \mathrm{~cm}$ biopsy needle & $\mu \mathrm{CT}$ in ideal environment & OP: $0.69 \pm 0.29$ \\
\hline $\begin{array}{l}\text { Damato } \\
\text { et } \mathbf{a}^{90}\end{array}$ & 2014 & $\begin{array}{l}\text { Ascension trakSTAR, } \\
\text { DC }\end{array}$ & Model $90,0.9 \mathrm{~mm}$ & $\begin{array}{l}\text { Post registration, in an ideal } \\
\text { environment, EMT versus } C T\end{array}$ & $0.6 \pm 0.2$ \\
\hline
\end{tabular}

Abbreviations: AC, alternating current; CT, computed tomography; DC, direct current; EMT, electromagnetic tracking; FG, field generator; OR, operating room; IP, in-plane; OP, out-of-plane, representing accuracy in catheter tip identification; TRUS, transrectal ultrasound.

to the limited slice thickness between ultrasound axial images and uncertainties in positional encoding during images scanning. As a result, the rigid registration can be rough and the errors in catheter reconstruction using transferred EMT acquisitions can be much greater than the corresponding intrinsic EMT tracking errors. A better way to register the two coordinate systems is to combine an optical tracking system with the EMT system by attaching optical markers to the FG and to the implant template/ stepper unit, which can improve registration accuracy greater than $0.5 \mathrm{~mm}$.

In the report by Bharat et al, ${ }^{87}$ a comprehensive registration scheme was employed. A reference electromagnetic sensor was used to remove the dependence of relative position variation between the FG and the template grid. All EMT data was converted to the coordinate frame of the reference sensor $\mathrm{C}_{\mathrm{Ref}}$ before conversion to the template grid coordinate system $\mathrm{C}_{\text {Grid }}$ (in a typical prostate HDR planning system, the $\mathrm{C}_{\text {Grid }}$ is the same as the $\mathrm{C}_{\mathrm{RT} \text { lan }}$ mentioned previously). By introducing two additional electromagnetic sensors attached to the ultrasound probe, the pixels on TRUS images can be associated with the $\mathrm{C}_{\mathrm{Ref}}$ coordinate system, and the manually reconstructed catheters in TRUS images can be correlated to the $\mathrm{C}_{\mathrm{Ref}}$ as well. The reconstructed catheters in corresponding CT images are converted to the $\mathrm{C}_{\mathrm{Ref}}$ coordinate system after registering $\mathrm{CT}$ images to the TRUS image data set. Instead of using points from both the posterior catheter tips and the template grid, as we described previously, for the calculation of the transformation matrix from $\mathrm{C}_{\text {Ref }}$ to $\mathrm{C}_{\text {Grid }}$, points were drawn exclusively from the template grid. It seems that the authors from this group do not have access to a real treatment planning system, as the transformations from TRUS and CT image coordinates to $\mathrm{C}_{\text {Grid }}$ are built into the planning system, and hence these transformations are not necessary in a clinical situation. In their study, catheters in a prostate phantom were scanned with both TRUS and CT, and the corresponding catheter reconstructions were compared with those from the EMT system in both a controlled ideal environment and an operating room environment. In the ideal environment, the discrepancies of reconstruction results between EMT and TRUS were $0.7 \pm 0.3 \mathrm{~mm}$ (maximum $1.7 \mathrm{~mm}$ ) and $0.1 \pm 0.1 \mathrm{~mm}$ (maximum $0.2 \mathrm{~mm}$ ) in the in-plane and out-of-plane directions, respectively. The corresponding discrepancies in the operating room environment were $0.6 \pm 0.3 \mathrm{~mm}$ (maximum $1.5 \mathrm{~mm}$ ) and $0.4 \pm 0.2 \mathrm{~mm}$ (maximum $0.6 \mathrm{~mm}$ ), respectively.

By registering EMT and CT dwell positions, Damato et al developed an error detection algorithm that can detect errors in catheter digitization during treatment planning. ${ }^{90} \mathrm{~A}$ trackSTAR EMT system (similar to the one we used) and two Model 90 sensors were used in their EMT system. Their residual mean error per catheter was $0.6 \pm 0.2 \mathrm{~mm}$, with a maximum error of $1.3 \pm 0.7 \mathrm{~mm}$. By analyzing the mean and maximum registration error, their algorithm was able to identify a swap/ partial swap of catheter number (when error was $\geq 2.6 \mathrm{~mm}$ ) and catheter tip shift (when shift was $>1.8 \pm 0.4 \mathrm{~mm}$ ), with $100 \%$ sensitivity and specificity. Their report was based on a phantom study in an ideal environment. The application of their method in a real clinical setup needs to be further validated. 


\section{Calibration}

While noise can be reduced by averaging and filtering raw data, distortion from metal interference can only be corrected with proper calibration. Assuming the FG location and its position relative to the surrounding sources of metal interference are fixed, the distortion can be corrected through a calibration scheme calculated using premeasured data. Kindratenko reviewed most of the calibration methods in use and described the pros and cons for each method. ${ }^{91}$ The calibration methods in most cases are application-dependent. In EMT, the Hardy multiquadric method, ${ }^{91}$ which is essentially a scattered data interpolation, is a good option. The Hardy multiquadric method is accurate in a premeasured space. However, corrections outside the premeasured space are not reliable. A quality assurance phantom with known catheter positions (as shown in Figure 3) can be used for calculating calibration profiles. It can be placed in several adjacent locations so that the acquired premeasured data can cover needle positions in most prostate implants. The Hardy multiquadric method can be briefly described as follows.

Given measured $N$ calibration points $\mathrm{P}_{i}(i=1$ to $N)$ and their corresponding real positions $\mathrm{Q}_{i}(i=1$ to $N$ ), a weighting vector $A$ can be calculated for each coordinate so that:

$$
W \cdot A=Q
$$

where

$$
W_{i, j}=\left(\left(P_{i}-P_{j}\right)^{2}+\varepsilon^{2}\right)^{1 / 2}, \quad i, j=1 \text { to } N
$$

is the system matrix and $\varepsilon$ is the shape parameter, the value of which is chosen by experience and is usually between 2 and 10 . The weighting vector $A$ can be solved as:

$$
A=W^{-1} \cdot Q
$$

To calibrate live measured data points $\bar{P}_{i}(i=1$ to $M$ ), a new system matrix $\bar{W}$ is calculated and multiplied by the weighting vector $A$,

$$
\bar{Q}=\bar{W} \cdot A
$$

where

$$
\bar{W}_{i, j}=\left(\left(\bar{P}_{i}-P_{j}\right)^{2}+\varepsilon^{2}\right)^{1 / 2}, \quad i=1 \text { to } M, j=1 \text { to } N
$$

and $\bar{Q}$ is calibrated positions for $\bar{P}$.

\section{Catheter displacement in HDR brachytherapy}

Another issue with HDR brachytherapy is interfraction catheter displacement and its effect on dosimetry. Our group first noticed this problem in $1995^{92}$ and further demonstrated a mean $2.0 \mathrm{~cm}$ displacement between fraction 1 and 2 using fluoroscopy in $2001 .{ }^{93}$ Due to the high dose gradients in an HDR treatment plan, any unintended movement of a catheter relative to the target and critical organs may result in significant changes in dosimetry. However, such movement may not be fully avoided due to changes in patient position, internal organ motion, and tissue swelling/edema. Practitioners and researchers have been investigating the magnitude of catheter displacements and their effects on dosimetry by using films, ${ }^{94}$ fluoroscopy images,${ }^{93}$ helical CT, ${ }^{95-100}$ cone beam CT, ${ }^{101,102}$ or CT/MR scans. ${ }^{103}$ These investigations have yielded the following results. Firstly, catheters have their most significant movement in the caudal direction, ${ }^{94}$ and mostly in the range of 5-10 mm. Secondly, their displacement depends on the type of template/applicator being used, and on the immobilization/suture method employed. Mikami et al reported much smaller median displacements $(1 \mathrm{~mm}$ at 21 hours and $2 \mathrm{~mm}$ at 45 hours) with their unique ambulatory technique. ${ }^{97}$ Thirdly, catheter displacement is time interval/fraction number-dependent. Holly et al reported that even at the first treatment fraction, a mean displacement of $11 \mathrm{~mm}$ from the planning CT was noticed. ${ }^{101}$ Whitaker et al did a similar study and found a mean displacement of $7.5 \mathrm{~mm}$ between planning and treatment. ${ }^{99} \mathrm{As}$ a result, using images acquired at the time of the first fraction as reference ${ }^{96}$ may not truly reflect the scale of displacement. Fourthly, internal movement of the catheters may not be reflected by the catheter free length (external length) outside the template. ${ }^{95}$ The target may shift off from the catheters inside the body, while keeping the outside template and catheters unchanged. Fifth and finally, fiducial markers, instead of bony structures, should be used for registration between subsequent fractions and the reference image set, even though their location relative to the target may migrate as well. ${ }^{94}$ Catheter displacement can be corrected by changing source dwell positions, or by physical readvancement of catheters before treatment; it may also be compensated for by using a large clinical target volume margin. Although treatment dosimetry is improved after this correction, it remains inferior to the corresponding original plans in most cases. To address this problem, we are investigating the use of EMT to improve this process. By registering to external markers or to implanted radiofrequency transponders, EMT can be used to verify catheter 
reconstruction before treatment delivery. As there is no added ionizing radiation dose to the patient, EMT can be safely reused to check any catheter displacement.

\section{Applicators with better/improved dosimetry}

Both industry vendors and researchers have been working on developing new devices and revising existing applicators to adapt to new clinical needs while improving their efficacy in traditional applications by improving dosimetry or extending coverage volume.

\section{Strut-adjusted volume implant}

The MammoSite applicator was first introduced into clinics for partial breast irradiation in 2002 with a single lumen and centered dwell position. ${ }^{104,105}$ Its spherical symmetric isodose distribution made it difficult in some situations to avoid potential overdose to adjacent skin and ribs. To address this limitation, an updated multi-lumen MammoSite with four catheters, one central and three equidistant at about $5 \mathrm{~mm}$ from the center, as well as the Contura with five catheters, one central and four equidistant at about $6 \mathrm{~mm}$ from the center, were developed. However, even with additional lumens, it was difficult in some patients to avoid overdosing the ribs and skin surface ( $<5 \mathrm{~mm}$ to the balloon surface). In 2011, the SAVI device became available. It has six, eight, or ten equidistant struts surrounding a central lumen, without any water-filled balloon and directly in contact with the cavity wall. For a typical 8+1 SAVI applicator (eight surrounding channels and one central), the maximum separation between the surrounding channels and the central channel varies between $5 \mathrm{~mm}$ at the ends to $27 \mathrm{~mm}$ at the center (compare to the fixed 5-6 mm distance from the surrounding channels to the central one in balloon devices). Because of these characteristics, the SAVI can provide more dose modulation than balloon-based devices. ${ }^{106,107}$ As a result, the dose to the skin, ribs, and pectoralis muscle can be significantly reduced while maintaining coverage of the planning target volume. As no spacer (water-filled balloon) separates the surrounding catheters from the target tissue, dose heterogeneity is usually higher and the $\mathrm{V}_{200}$ is limited to $20 \mathrm{cc}$, instead of $10 \mathrm{cc}$, as in the case of treatments employing balloon devices.

\section{Applicators for gynecology}

Several gynecologic applicators have recently been made available to the clinician to improve dosimetry, anatomic versatility, and coverage area, when compared with traditional applicators. The conventional single-channel vaginal cylinder has been extended to a multi-channel vaginal cylinder with one central channel and eight peripheral channels (Nucletron, Elekta AB). Studies have shown that with similar coverage of the clinical target volume, the multi-channel vaginal cylinder provides significantly improved dosimetry to the rectum. ${ }^{54}$ In 2009, Nucletron launched two new combined intracavitary/interstitial gynecologic applicators. The interstitial ring applicator is based on the Vienna applicator ${ }^{108}$ and is used when tumor extension exceeds $3.5 \mathrm{~cm}$ at the ring level, $2.5 \mathrm{~cm}$ at the point A level, and $2.2 \mathrm{~cm}$ at a distance $3-4 \mathrm{~cm}$ cranial to the ring surface or if the tumor is not symmetrically distributed around the tandem. ${ }^{109}$ The Utrecht interstitial Fletcher-like applicator uses the ovoids as templates for needle insertion.

\section{Discussion and conclusion}

More institutions have adopted the new GEC-ESTRO guidelines for image-guided brachytherapy. The increasing use of MR imaging as the sole imaging modality in gynecologic cases has made MR-compatible catheters and applicators more important. Although plastic applicators introduce minimum artifact and interference in MR scans, their size is not ideal in some situations. Their structural strength poses another potential risk for the procedure, as demonstrated by the recent recall of some plastic applicators. The titanium applicators, however, have substantial problems with artifact, dependent on relative position and scanning sequence. Again, higher artifact width may not be associated with lower reconstruction accuracy. Instead, it is the uncertainty of this artifact width that results in higher variation of reconstruction accuracy. MR image-guided brachytherapy with titanium applicators should be carefully checked, and an additional CT scan may be necessary due to large uncertainties in applicator reconstruction. Further investigation is necessary to improve catheter and applicator reconstruction in MR.

Recently, the joint American Association of Physicists in Medicine/GEC-ESTRO committee reviewed the uncertainties in brachytherapy. ${ }^{110}$ The advanced catheter technologies discussed in this paper are essentially trying to minimize the uncertainties and errors in brachytherapy. The using of MR imaging can minimize the uncertainty in delineating targets and organs at risk. Although catheter reconstruction with MR imaging may introduce additional uncertainties, it can be minimized by registering the MR images to CT images. Similarly, the EMT can be used to reduce the uncertainty in catheter reconstruction and correct interfraction catheter displacements. The accuracy of the EMT system can be improved with calibration schemes. 
As the uncertainties in brachytherapy being reduced, many new hypofractionation and focal tumor boost protocols have been developed. ${ }^{111-113}$ Hypofractionated HDR monotherapy for prostate cancer has been gaining more attention from investigators, not only because of reduced in-hospital time for the patient, but also because of the low $\alpha / \beta$ ratio ( 1 to 2 Gy) of prostate cancer. Prada et al reported using treatments of a single HDR fraction of 19 Gy for patients with favorable prostate cancer. ${ }^{114}$ The treatments were well tolerated, and the biochemical control at 32 months was similar to that in patients treated with LDR prostate seed implants. In Canada, Morton et al treated patients with intermediate-risk prostate cancer with intensity modulated radiation therapy followed by a single HDR fraction of $15 \mathrm{~Gy}$ as a boost treatment. ${ }^{111}$ As the prescription doses in these hypofractionated treatments are significantly higher than in conventional treatments, the precision of treatment planning is critical. Ultrasound-based planning has the advantage of in situ imaging, planning, and treatment, and a satisfactory, reliable plan could be generated and delivered using this technique. However, catheter reconstruction based on ultrasound imaging can sometimes be very challenging. EMT provides a better way to not only improve the accuracy and speed of catheter reconstruction, but also reduces the degree of human error associated with it. Initial phantom studies show very promising results and further clinical tests are required to validate this technique in the treatment of real patients.

Studies have shown that breast cancers also have a low $\alpha / \beta$ ratio (5 Gy), which prompted investigators to hypofractionate their treatment similarly to prostate cancer. New 2-day fractionation schemes have been demonstrated in different national and institutional trials. At our institution, we started a Phase II trial in 2004 using the MammoSite applicator to deliver four fractions of APBI in two treatment days (7 Gy/ fx for a total of $28 \mathrm{~Gy}$ ). The initial published results of this study have demonstrated acceptable Grade II/III chronic toxicity rates and comparable local control, survival, and cosmesis when compared with the standard 5-day APBI treatment course with MammoSite. ${ }^{115-117}$ In 2009, SenoRx Inc., the company that produces the Contura applicator, initiated a multi-institutional study investigating the use of the Contura balloon brachytherapy device in a 2-day regimen at three specific dose levels, ie, 7 Gy $\times 4,8.25$ Gy $\times 3$, and $10.25 \mathrm{~Gy} \times 2$. The initial study of 30 patients treated at the 7 Gy $\times 4$ fraction dose level and followed for 6 months demonstrated the feasibility of this short-course APBI. ${ }^{118}$ The optimized dosimetry provided by newly developed multi-catheter applicators is important in reducing doses to critical structures while maintaining target coverage. As new catheter technologies come to be applied in the clinic, patient care can be substantially improved.

\section{Disclosure}

The authors report no conflicts of interest in this work.

\section{References}

1. Galvin JM, Ezzell G, Eisbrauch A, et al. Implementing IMRT in clinical practice: a joint document of the American Society for Therapeutic Radiology and Oncology and the American Association of Physicists in Medicine. Int J Radiat Oncol. 2004;58(5):1616-1634.

2. Convery D, Rosenbloom M. The generation of intensity-modulated fields for conformal radiotherapy. Phys Med Biol. 1992;37(6):1359-1374.

3. Bortfeld TR, Kahler DL, Waldron TJ, Boyer AL. X-ray field compensation with multileaf collimators. Int J Radiat Oncol. 1994;28(3): 723-730.

4. Yu CX. Intensity-modulated arc therapy with dynamic multileaf collimation: an alternative to tomotherapy. Phys Med Biol. 1995;40(9): 1435.

5. Chino K, Silvain D, Grace A, Stubbs J, Stea B. Feasibility and safety of outpatient brachytherapy in 37 patients with brain tumors using the GliaSite radiation therapy system. Med Phys. 2008;35(7): 3383-3388.

6. Wernicke AG, Yondorf MZ, Peng L, et al. Phase I/II study of resection and intraoperative cesium-131 radioisotope brachytherapy in patients with newly diagnosed brain metastases. J Neurosurg. 2014;121(2): 338-348.

7. Chiu-Tsao S-T, Astrahan MA, Finger PT, et al. Dosimetry of (125)I and (103)Pd COMS eye plaques for intraocular tumors: report of Task Group 129 by the AAPM and ABS. Med Phys. 2012;39(10):6161-6184.

8. Jensen AW, Petersen IA, Kline RW, Stafford SL, Schomberg PJ, Robertson DM. Radiation complications and tumor control after 125I plaque brachytherapy for ocular melanoma. Int J Radiat Oncol Biol Phys. 2005;63(1):101-108.

9. Nag S, Quivey JM, Earle JD, Followill D, Fontanesi J, Finger PT. The American Brachytherapy Society recommendations for brachytherapy of uveal melanomas. Int J Radiat Oncol Biol Phys. 2003;56(2): 544-555.

10. Damato B, Patel I, Campbell IR, Mayles HM, Errington RD. Local tumor control after 106Ru brachytherapy of choroidal melanoma. Int J Radiat Oncol Biol Phys. 2005;63(2):385-391.

11. Voynov G, Heron DE, Lin CJ, et al. Intraoperative (125)I Vicryl mesh brachytherapy after sublobar resection for high-risk stage I non-small cell lung cancer. Brachytherapy. 2005;4(4):278-285.

12. Vicini FA, Chen PY, Fraile M, et al. Low-dose-rate brachytherapy as the sole radiation modality in the management of patients with early-stage breast cancer treated with breast-conserving therapy: preliminary results of a pilot trial. Int J Radiat Oncol Biol Phys. 1997;38(2):301-310.

13. Yu Y, Anderson LL, Li Z, et al. Permanent prostate seed implant brachytherapy: report of the American Association of Physicists in Medicine Task Group No 64. Med Phys. 1999;26(10):2054-2076.

14. Nag S, Beyer D, Friedland J, Grimm P, Nath R. American Brachytherapy Society (ABS) recommendations for transperineal permanent brachytherapy of prostate cancer. Int J Radiat Oncol Biol Phys. 1999; 44(4):789-799.

15. International Commission on Radiation Units and Measurements. Dose and volume specification for reporting intracavitary therapy in gynecology. Bethesda, MD, USA: International Commission on Radiation Units and Measurements; 1985. Available from: http://www.osti. gov/scitech/servlets/purl/672130/. Accessed May 10, 2015.

16. Nath R, Urdaneta N, Bolanis N, Peschel R. A dosimetric analysis of Morris, Fletcher, and Henschke systems for treatment of uterine cervix carcinoma. Int J Radiat Oncol Biol Phys. 1991;21(4):995-1003. 
17. Davis BJ, Horwitz EM, Lee WR, et al. American Brachytherapy Society consensus guidelines for transrectal ultrasound-guided permanent prostate brachytherapy. Brachytherapy. 2012;11(1):6-19.

18. Rosenthal SA, Bittner NHJ, Beyer DC, et al. American Society for Radiation Oncology (ASTRO) and American College of Radiology (ACR) practice guideline for the transperineal permanent brachytherapy of prostate cancer. Int J Radiat Oncol. 2011;79(2):335-341.

19. Zelefsky MJ, Kuban DA, Levy LB, et al. Multi-institutional analysis of long-term outcome for stages T1-T2 prostate cancer treated with permanent seed implantation. Int J Radiat Oncol. 2007;67(2): 327-333.

20. Sylvester J, Grimm P, Naidoo D, Bilik J, Miller A, Wong J. First report on the use of a thinner I-125 radioactive seed within 20-gauge needles for permanent radioactive seed prostate brachytherapy: Evaluation of postimplant dosimetry and acute toxicity. Brachytherapy. 2013;12(4): 375-381.

21. Hsu IC, Yamada Y, Assimos DG, et al. ACR appropriateness criteria high-dose-rate brachytherapy for prostate cancer. Brachytherapy. 2014; 13(1):27-31

22. White EC, Kamrava MR, Demarco J, et al. High-dose-rate prostate brachytherapy consistently results in high quality dosimetry. Int $J$ Radiat Oncol Biol Phys. 2013;85(2):543-548.

23. Fowble B. Ipsilateral breast tumor recurrence following breastconserving surgery for early-stage invasive cancer. Acta Oncol. 1999;38 Suppl 13:9-17.

24. Veronesi U, Luini A, Del Vecchio M, et al. Radiotherapy after breastpreserving surgery in women with localized cancer of the breast. N Engl J Med. 1993;328(22):1587-1591.

25. Abbott AM, Portschy PR, Lee C, et al. Prospective multicenter trial evaluating balloon-catheter partial-breast irradiation for ductal carcinoma in situ. Int J Radiat Oncol Biol Phys. 2013;87(3):494-498.

26. Israel PZ, Robbins A, Shroff P, Brown S, McLaughlin M, Pope K. Three-year clinical outcome using the Contura multilumen balloon breast brachytherapy catheter to deliver accelerated partial breast irradiation (APBI): improving radiation standards for the optimal application of APBI. Brachytherapy. 2012;11(4):316-321.

27. Cuttino LW, Arthur DW, Vicini F, Todor D, Julian T, Mukhopadhyay N. Long-term results from the Contura multilumen balloon breast brachytherapy catheter Phase 4 registry trial. Int J Radiat Oncol. 2014 90(5):1025-1029.

28. Shaitelman SF, Vicini FA, Beitsch P, Haffty B, Keisch M, Lyden M. Five-year outcome of patients classified using the American Society for Radiation Oncology consensus statement guidelines for the application of accelerated partial breast irradiation: an analysis of patients treated on the American Society of Breast Surgeons MammoSite Registry Trial. Cancer. 2010;116(20):4677-4685.

29. Vicini F, Beitsch P, Quiet C, et al. Five-year analysis of treatment efficacy and cosmesis by the American Society of Breast Surgeons Mammosite Breast Brachytherapy Registry Trial in patients treated with accelerated partial breast irradiation. Int J Radiat Oncol Biol Phys. 2011;79(3):808-817.

30. Vicini FA, Keisch M, Shah C, et al. Factors associated with optimal long-term cosmetic results in patients treated with accelerated partial breast irradiation using balloon-based brachytherapy. Int J Radiat Oncol Biol Phys. 2012;83(2):512-518.

31. Yashar CM, Scanderbeg D, Kuske R, et al. Initial clinical experience with the strut-adjusted volume implant (SAVI) breast brachytherapy device for accelerated partial-breast irradiation (APBI): first 100 patients with more than 1 year of follow-up. Int J Radiat Oncol Biol Phys. 2011; 80(3):765-770.

32. Tod MC, Meredith WJ. A dosage system for use in the treatment of cancer of the uterine cervix. Br J Radiol. 1938;11(132):809-824.

33. Tod M, Meredith WJ. Treatment of cancer of the cervix uteri, a revised Manchester method. Br J Radiol. 1953;26(305):252-257.

34. Viswanathan AN, Erickson BA. Three-dimensional imaging in gynecologic brachytherapy: a survey of the American Brachytherapy Society. Int J Radiat Oncol Biol Phys. 2010;76(1):104-109.
35. International Commission on Radiation Units and Measurements. Dose and volume system for reporting intracavitary treatment in gynecology. Report 38. Bethesda, MD, USA: International Commission on Radiation Units; 1985. Available from: http://www.icru.org/home/reports/ dose-and-volume-specification-for-reporting-intracavitary-therapy-ingynecology-report-38. Accessed May 10, 2015.

36. Haie-Meder C, Pötter R, Van Limbergen E, et al; Gynaecological (GYN) GEC-ESTRO Working Group. Recommendations from Gynaecological (GYN) GEC-ESTRO Working Group (I): concepts and terms in 3D image based 3D treatment planning in cervix cancer brachytherapy with emphasis on MRI assessment of GTV and CTV. Radiother Oncol. 2005;74(3):235-245.

37. Pötter R, Haie-Meder C, Limbergen EV, et al; GEC ESTRO Working Group. Recommendations from gynaecological (GYN) GEC ESTRO working group (II): concepts and terms in 3D image-based treatment planning in cervix cancer brachytherapy-3D dose volume parameters and aspects of 3D image-based anatomy, radiation physics, radiobiology. Radiother Oncol. 2006;78(1):67-77.

38. Nag S, Cardenes H, Chang S, et al. Proposed guidelines for imagebased intracavitary brachytherapy for cervical carcinoma: report from Image-Guided Brachytherapy Working Group. Int J Radiat Oncol. 2004;60(4):1160-1172.

39. Lee LJ, Das IJ, Higgins SA, et al. American Brachytherapy Society consensus guidelines for locally advanced carcinoma of the cervix. Part III: low-dose-rate and pulsed-dose-rate brachytherapy. Brachytherapy. 2012;11(1):53-57.

40. Viswanathan AN, Beriwal S, De Los Santos JF, et al. American Brachytherapy Society consensus guidelines for locally advanced carcinoma of the cervix. Part II: high-dose-rate brachytherapy. Brachytherapy. 2012;11(1):47-52.

41. Viswanathan AN, Thomadsen B; American Brachytherapy Society Cervical Cancer Recommendations Committee, American Brachytherapy Society. American Brachytherapy Society consensus guidelines for locally advanced carcinoma of the cervix. Part I: general principles. Brachytherapy. 2012;11(1):33-46.

42. Kapur T, Egger J, Damato A, Schmidt EJ, Viswanathan AN. 3-T MR-guided brachytherapy for gynecologic malignancies. Magn Reson Imaging. 2012;30(9):1279-1290.

43. Viswanathan AN, Szymonifka J, Tempany-Afdhal CM, O'Farrell DA, Cormack RA. A prospective trial of real-time magnetic resonanceguided catheter placement in interstitial gynecologic brachytherapy. Brachytherapy. 2013;12(3):240-247.

44. Lakosi F, Antal G, Vandulek C, et al. Open MR-guided high-dose-rate (HDR) prostate brachytherapy: feasibility and initial experiences open MR-guided high-dose-rate (HDR) prostate brachytherapy. Pathol Oncol Res. 2011;17(2):315-324.

45. Nomden CN, de Leeuw AA, Van Limbergen E, et al. Multicentre treatment planning study of MRI-guided brachytherapy for cervical cancer: comparison between tandem-ovoid applicator users. Radiother Oncol. 2013;107(1):82-87.

46. Jürgenliemk-Schulz IM, Lang S, Tanderup K, et al. Variation of treatment planning parameters (D90 HR-CTV, D2cc for OAR) for cervical cancer tandem ring brachytherapy in a multicentre setting: Comparison of standard planning and 3D image guided optimisation based on a joint protocol for dose-volume constraints. Radiother Oncol. 2010;94(3): 339-345.

47. Haack S, Nielsen SK, Lindegaard JC, Gelineck J, Tanderup K. Applicator reconstruction in MRI 3D image-based dose planning of brachytherapy for cervical cancer. Radiother Oncol. 2009;91(2):187-193.

48. Kim Y, Muruganandham M, Modrick JM, Bayouth JE. Evaluation of artifacts and distortions of titanium applicators on 3.0-Tesla MRI: feasibility of titanium applicators in MRI-guided brachytherapy for gynecological cancer. Int J Radiat Oncol. 2011;80(3):947-955.

49. Schindel J, Muruganandham M, Pigge FC, Anderson J, Kim Y. Magnetic resonance imaging (MRI) markers for MRI-guided high-dose-rate brachytherapy: novel marker-flange for cervical cancer and marker catheters for prostate cancer. Int J Radiat Oncol Biol Phys. 2013;86(2):387-393. 
50. Petit S, Wielopolski P, Rijnsdorp R, Mens J-W, Kolkman-Deurloo I-K. MR guided applicator reconstruction for brachytherapy of cervical cancer using the novel titanium Rotterdam applicator. Radiother Oncol. 2013;107(1):88-92.

51. Kim JS, Lee YS, Lim YK, Park SY, Kim JY. Reconstruction of a Fletcher-type applicator with a CT/MR compatible catheter using MR imaging for cervical cancer brachytherapy. J Korean Phys Soc. 2010; 56(3):880-886.

52. Nomden CN, de Leeuw AA, Moerland MA, Roesink JM, Tersteeg RJ, Jürgenliemk-Schulz IM. Clinical use of the Utrecht applicator for combined intracavitary/interstitial brachytherapy treatment in locally advanced cervical cancer. Int J Radiat Oncol. 2012;82(4): 1424-1430.

53. Johnson SB, Zhou J, Jolly S, Guo B, Young L, Prisciandaro JI. The dosimetric impact of single, dual, and triple tandem applicators in the treatment of intact uterine cancer. Brachytherapy. 2014;13(3):268-274.

54. Kim H, Rajagopalan MS, Houser C, Beriwal S. Dosimetric comparison of multichannel with one single-channel vaginal cylinder for vaginal cancer treatments with high-dose-rate brachytherapy. Brachytherapy. 2014;13(3):263-267.

55. Klopp AH, Mourtada F, Yu ZH, et al. Pilot study of a computed tomography-compatible shielded intracavitary brachytherapy applicator for treatment of cervical cancer. Pract Radiat Oncol. 2013;3(2): $115-123$.

56. Gifford K, Han T, Mourtada F, Eifel P. SU-F-19A-04: dosimetric evaluation of a novel CT/MR compatible Fletcher applicator for intracavitary brachytherapy of the cervix uteri. Med Phys. 2014;41(6):388-388.

57. Castle KO, Klopp AH, Rechner LA, et al. Dose reduction to rectum and bladder using the Fletcher CT/MR shielded applicator for cervical cancer. Brachytherapy. 2014;13:S32.

58. Di Mambro A, Giuliani C, Ammannati F, et al. A single-institution restrospective experience of brachytherapy in the treatment of pituitary tumors: transsphenoidal approach combined with Ir-192-afterloading catheters. $J$ Endocrinol Invest. 2010;33(7):455-460.

59. Budrukkar A, Bahl G, Bhalavat R, et al. High-dose-rate brachytherapy boost for carcinoma of external auditory canal. Brachytherapy. 2009; 8(4):392-395.

60. Garran C, Montesdeoca N, Martinez-Mongel R. Treatment of upper gum carcinoma with high-dose-rate customized-mold brachytherapy. Brachytherapy. 2008;7(3):267-269.

61. Matsumoto K, Sasaki T, Shioyama Y, et al. Treatment outcome of high-dose-rate interstitial radiation therapy for patients with stage I and II mobile tongue cancer. Jpn J Clin Oncol. 2013;43(10):1012-1017.

62. Libby B, Sheng K, McLawhorn R, et al. Use of megavoltage computed tomography with image registration for high-dose rate treatment planning of an oral tongue cancer using a custom oral mold applicator with embedded lead shielding. Brachytherapy. 2011;10(4):340-344.

63. Meccariello G, Merks JH, Pieters BR, et al. Endoscopic management of Ewing's sarcoma of ethmoid sinus within the AMORE framework: a new paradigm. Int J Pediatr Otorhinolaryngol. 2013;77(1):139-143.

64. Bartochowska A, Skowronek J, Wierzbicka M, Leszczynska M, Szyfter W. The role of high-dose-rate and pulsed-dose-rate brachytherapy in the management of recurrent or residual stomal tumor after total laryngectomy. Laryngoscope. 2013;123(3):657-661.

65. Mazeron JJ, Ardiet JM, Haie-Meder C, et al. GEC-ESTRO recommendations for brachytherapy for head and neck squamous cell carcinomas. Radiother Oncol. 2009;91(2):150-156.

66. Narayana A, Cohen GN, Zaider M, et al. High-dose-rate interstitial brachytherapy in recurrent and previously irradiated head and neck cancers - preliminary results. Brachytherapy. 2007;6(2):157-163.

67. Ziemlewski A, Zienkiewicz J, Serkies K, Badzio A. Preliminary report of pulsed dose rate brachytherapy in head-and-neck cancer. Strahlenther Onkol. 2007;183(9):512-516.

68. Doyle LA, Harrison AS, Cognetti D, et al. Reirradiation of head and neck cancer with high-dose-rate brachytherapy: a customizable intraluminal solution for postoperative treatment of tracheal mucosa recurrence. Brachytherapy. 2011;10(2):154-158.
69. Folkert MR, Bilsky MH, Cohen GN, et al. Intraoperative and percutaneous iridium-192 high-dose-rate brachytherapy for previously irradiated lesions of the spine. Brachytherapy. 2013;12(5):449-456.

70. Aggarwal R, Patel FD, Kapoor R, Kang M, Kumar P, Sharma SC. Evaluation of high-dose-rate intraluminal brachytherapy by percutaneous transhepatic biliary drainage in the palliative management of malignant biliary obstruction - a pilot study. Brachytherapy. 2013;12(2):162-170.

71. Tam TY, Mukherjee S, Farrell T, Morgan D, Sur R. Endoscopic brachytherapy for obstructive colorectal cancer. Brachytherapy. 2009; 8(3):313-317.

72. Houtmeyers P, Breusegem C, Ceelen W, et al. Intraoperative highdose-rate brachytherapy (IBT) for locally unresectable intraabdominal malignancy. Acta Chir Belg. 2007;107(5):523-528.

73. Dimopoulos JC, Petrow P, Tanderup K, et al. Recommendations from Gynaecological (GYN) GEC-ESTRO Working Group (IV): basic principles and parameters for MR imaging within the frame of image based adaptive cervix cancer brachytherapy. Radiother Oncol. 2012;103(1): 113-122.

74. Tanderup K, Viswanathan AN, Kirisits C, Frank SJ. Magnetic resonance image guided brachytherapy. Semin Radiat Oncol. 2014;24(3): 181-191.

75. Lewin JS, Duerk JL, Jain VR, Petersilge CA, Chao CP, Haaga JR. Needle localization in MR-guided biopsy and aspiration: effects of field strength, sequence design, and magnetic field orientation. AJR Am J Roentgenol. 1996;166(6):1337-1345.

76. Peikari M, Chen TK, Lasso A, Heffter T, Fichtinger G, Burdette EC. Characterization of ultrasound elevation beamwidth artifacts for prostate brachytherapy needle insertion. Med Phys. 2012;39(1):246-256.

77. Limbacher A, Sebastian E, Yan D, Zhou J. Discrepancies of catheter reconstruction in ultrasound (US) image guided prostate high dose rate (HDR) brachytherapy and their effects to dosimetry. Brachytherapy. 2014;13.S114-S115.

78. Schmid M, Crook JM, Batchelar D, et al. A phantom study to assess accuracy of needle identification in real-time planning of ultrasoundguided high-dose-rate prostate implants. Brachytherapy. 2013;12(1): $56-64$.

79. Wilkinson DA, Kolar MD. Failure modes and effects analysis applied to high-dose-rate brachytherapy treatment planning. Brachytherapy. 2013;12(4):382-386.

80. Zhou J, Sebastian E, Mangona V, Yan D. Real-time catheter tracking for high-dose-rate prostate brachytherapy using an electromagnetic 3D-guidance device: a preliminary performance study. Med Phys. 2013;40(2):021716.

81. Penzkofer T, Isfort $\mathrm{P}$, Bruners $\mathrm{P}$, et al. Robot arm based flat panel CT-guided electromagnetic tracked spine interventions: phantom and animal model experiments. Eur Radiol. 2010;20(11):2656-2662.

82. Lei P, Moeslein F, Wood BJ, Shekhar R. Real-time tracking of liver motion and deformation using a flexible needle. Int J Comput Assist Radiol Surg. 2011;6(3):435-446.

83. San José Estépar R, Stylopoulos N, Ellis RE, et al. Towards scarless surgery: an endoscopic-ultrasound navigation system for transgastric access procedures. Med Image Comput Comput Assist Interv. 2006; 9 Pt 1:445-453.

84. Patronik NA, Ota T, Zenati MA, Riviere CN. A miniature mobile robot for navigation and positioning on the beating heart. IEEE Trans Robot. 2009;25(5):1109-1124.

85. Cherpak A, Ding W, Hallil A, Cygler JE. Evaluation of a novel 4D in vivo dosimetry system. Med Phys. 2009;36(5):1672-1679.

86. Nixon MA, McCallum BC, Fright WR, Price NB. The effects of metals and interfering fields and on electromagnetic trackers. Presence: Teleoperators and Virtual Environments. 1998;7(2):204-218.

87. Bharat S, Kung C, Dehghan E, et al. Electromagnetic tracking for catheter reconstruction in ultrasound-guided high-dose-rate brachytherapy of the prostate. Brachytherapy. 2014;13(6):640-650.

88. Poulin E, Racine E, Binnekamp D, Beaulieu L. Fast, automatic, and accurate catheter reconstruction in HDR brachytherapy using an electromagnetic 3D tracking system. Med Phys. 2015;42(3):1227-1232. 
89. Balachandran R, Fitzpatrick JM. Iterative solution for rigid-body point-based registration with anisotropic weighting SPIE Medical Imaging. 2009:7261:72613D.

90. Damato AL, Viswanathan AN, Don SM, Hansen JL, Cormack RA. A system to use electromagnetic tracking for the quality assurance of brachytherapy catheter digitization. Med Phys. 2014;41(10):101702.

91. Kindratenko V. A survey of electromagnetic position tracker calibration techniques. Virtual Real. 2000;5(3):169-182.

92. Martinez A, Gonzalez J, Stromberg J, et al. Conformal prostate brachytherapy: initial experience of a phase I/II dose-escalating trial. Int J Radiat Oncol. 1995;33(5):1019-1027.

93. Martinez AA, Pataki I, Edmundson G, Sebastian E, Brabbins D, Gustafson G. Phase II prospective study of the use of conformal highdose-rate brachytherapy as monotherapy for the treatment of favorable stage prostate cancer: a feasibility report. Int J Radiat Oncol Biol Phys. 2001;49(1):61-69.

94. Damore S, Syed A, Puthawala A, Sharma A. Needle displacement during HDR brachytherapy in the treatment of prostate cancer. Int $J$ Radiat Oncol Biol Phys. 2000;46(5):1205-1211.

95. Hoskin PJ, Bownes PJ, Ostler P, Walker K, Bryant L. High dose rate afterloading brachytherapy for prostate cancer: catheter and gland movement between fractions. Radiother Oncol. 2003;68(3):285-288.

96. Simnor T, Li S, Lowe G, et al. Justification for inter-fraction correction of catheter movement in fractionated high dose-rate brachytherapy treatment of prostate cancer. Radiother Oncol. 2009;93(2):253-258.

97. Mikami M, Yoshida K, Takenaka T, et al. Daily computed tomography measurement of needle applicator displacement during high-dose-rate interstitial brachytherapy for previously untreated uterine cervical cancer. Brachytherapy. 2011;10(4):318-324.

98. Damato AL, Cormack RA, Viswanathan AN. Characterization of implant displacement and deformation in gynecologic interstitial brachytherapy. Brachytherapy. 2014;13(1):100-109.

99. Whitaker M, Hruby G, Lovett A, Patanjali N. Prostate HDR brachytherapy catheter displacement between planning and treatment delivery Radiother Oncol. 2011;101(3):490-494.

100. Mullokandov E, Gejerman G. Analysis of serial CT scans to assess template and catheter movement in prostate HDR brachytherapy. Int J Radiat Oncol Biol Phys. 2004;58(4):1063-1071.

101. Holly R, Morton GC, Sankreacha R, et al. Use of cone-beam imaging to correct for catheter displacement in high dose-rate prostate brachytherapy. Brachytherapy. 2011;10(4):299-305.

102. Foster W, Cunha JA, Hsu IC, Weinberg V, Krishnamurthy D, Pouliot J. Dosimetric impact of interfraction catheter movement in high-dose rate prostate brachytherapy. Int J Radiat Oncol Biol Phys. 2011;80(1):85-90.

103. Rey F, Chang C, Mesina C, Dixit N, Kevin Teo B-K, Lin LL. Dosimetric impact of interfraction catheter movement and organ motion on MRI/CT guided HDR interstitial brachytherapy for gynecologic cancer. Radiother Oncol. 2013;107(1):112-116.

104. Smith BD, Arthur DW, Buchholz TA, et al. Accelerated partial breast irradiation consensus statement from the American Society for Radiation Oncology (ASTRO). Int J Radiat Oncol. 2009;74(4): 987-1001.
105. Keisch M, Vicini F, Kuske RR, et al. Initial clinical experience with the MammoSite breast brachytherapy applicator in women with earlystage breast cancer treated with breast-conserving therapy. Int J Radiat Oncol Biol Phys. 2003;55(2):289-293.

106. Scanderbeg D, Yashar C, White G, Rice R, Pawlicki T. Evaluation of three APBI techniques under NSABP B-39 guidelines. J Appl Clin Med Phys. 2010;11(1):3021.

107. Yashar C. Counterpoint: the device with the most dose modulation capacity. Brachytherapy. 2011;10(6):436-439.

108. Kirisits C, Lang S, Dimopoulos J, Berger D, Georg D, Pötter R. The Vienna applicator for combined intracavitary and interstitial brachytherapy of cervical cancer: design, application, treatment planning, and dosimetric results. Int J Radiat Oncol Biol Phys. 2006;65(2): 624-630

109. Viswanathan AN, Kirisits C, Erickson BE, Pötter R. Gynecologic Radiation Therapy: Novel Approaches to Image-Guidance and Management. Springer Science and Business Media; 2010.

110. Kirisits C, Rivard MJ, Baltas D, et al. Review of clinical brachytherapy uncertainties: analysis guidelines of GEC-ESTRO and the AAPM. Radiother Oncol. 2014;110(1):199-212.

111. Morton G, Loblaw A, Cheung P, et al. Is single fraction 15 Gy the preferred high dose-rate brachytherapy boost dose for prostate cancer? Radiother Oncol. 2011;100(3):463-467.

112. Mason J, Al-Qaisieh B, Bownes P, et al. Multi-parametric MRI-guided focal tumor boost using HDR prostate brachytherapy: a feasibility study. Brachytherapy. 2014;13(2):137-145.

113. Kamrava M, Chung MP, Kayode O, et al. Focal high-dose-rate brachytherapy: a dosimetric comparison of hemigland vs conventional whole-gland treatment. Brachytherapy. 2013;12(5):434-441.

114. Prada PJ, Jimenez I, González-Suárez H, Fernández J, CuervoArango C, Mendez L. High-dose-rate interstitial brachytherapy as monotherapy in one fraction and transperineal hyaluronic acid injection into the perirectal fat for the treatment of favorable stage prostate cancer: treatment description and preliminary results. Brachytherapy 2012;11(2):105-110.

115. Chen PY, Shah C, Wilkinson J, et al. Clinical efficacy of 2- versus 5-day accelerated partial breast irradiation delivered via balloon-based brachytherapy: results of a matched pair analysis. Int J Radiat Oncol Biol Phys. 2012;84(3):S86.

116. Wilkinson JB, Martinez AA, Chen PY, et al. Four-year results using balloon-based brachytherapy to deliver accelerated partial breast irradiation with a 2-day dose fractionation schedule. Brachytherapy. 2012;11(2):97-104.

117. Chen PY, Martinez AA, Wallace M, et al. Comparative analysis of two distinct time-dose-fractionation schemes [2-day vs 5-day] for delivery of accelerated partial breast irradiation via the MammoSite ${ }^{\mathbb{R}}$ RTS applicator. Brachytherapy. 2010;9:S31.

118. Khan AJ, Vicini FA, Brown S, et al. Dosimetric feasibility and acute toxicity in a prospective trial of ultrashort-course accelerated partial breast irradiation (APBI) using a multi-lumen balloon brachytherapy device. Ann Surg Oncol. 2013;20(4):1295-1301.
Cancer Management and Research

\section{Publish your work in this journal}

Cancer Management and Research is an international, peer-reviewed open access journal focusing on cancer research and the optimal use of preventative and integrated treatment interventions to achieve improved outcomes, enhanced survival and quality of life for the cancer patient The journal welcomes original research, clinical \& epidemiological

\section{Dovepress}

studies, reviews \& evaluations, guidelines, expert opinion \& commentary, case reports \& extended reports. The manuscript management system is completely online and includes a very quick and fair peerreview system, which is all easy to use. Visit http://www.dovepress.com/ testimonials.php to read real quotes from published authors. 